\title{
RELEVÂNCIA DAS CARACTERÍSTICAS DOS CEO's NA ESTRUTURA DE CAPITAL DE EMPRESAS LISTADAS NO IBrX-100 DA BM\&FBOVESPA
}

\section{RELEVANCE OF CEO'S CHARACTERISTICS IN CAPITAL STRUCTURE OF COMPANIES LISTED IN THE IBrX-100 INDEX OF BM\&FBOVESPA}

\author{
Joyce Mariella Medeiros Cavalcanti \\ Doutoranda em Administração pela Universidade Federal de Minas Gerais. Mestre em Administração pela Universidade Federal do Rio \\ Grande do Norte. \\ Belo Horizonte, MG, Brasil \\ E-mail: joyce_mariella@yahoo.com.br \\ Renato Alfredo Lazo Paz \\ Mestrando em Administração pela Universidade Federal de Minas Gerais. \\ Belo Horizonte, MG, Brasil \\ E-mail: renato.lazo@gmail.com

\section{Bruno Perez Ferreira} \\ Doutorado em Administração pela Universidade Federal de Minas Gerais. Professor na Universidade Federal de Minas Gerais \\ Belo Horizonte, MG, Brasil \\ E-mail: brunoperez@face.ufmg.br \\ Hudson Fernandes Amaral \\ Doutorado em Sciences de Gestion, Université Pierre Mendes France, ESA - Grenoble II. Professor Titular da Universidade Federal de \\ Minas Gerais \\ Belo Horizonte, MG, Brasil \\ E-mail: hfamaral@face.ufmg.br \\ Anderson Luis Rezende Mól \\ Doutor em Administração pela Uiversidade Federal de Lavras. Professor Adjunto da Universidade Federal do Rio Grande do Norte \\ Natal, RN, Brasil \\ E-mail: mol@ufrnet.br
}

\section{RESUMO}

Com base no pressuposto teórico dos modelos de agência que postula sobre a relação entre estrutura de capital corporativa e estilo de gestão dos CEO's, o objetivo deste artigo é analisar quais características individuais dos CEO's quanto à idade, sexo, tempo de mandato na empresa, presença de relação familiar, tipo de remuneração e curso de graduação obtido influenciam na estrutura de capital corporativa das empresas listadas no IBrX-100 da BM\&FBOVESPA no período de 2009 a 2013, mantendo fatores relacionados às características da firma constantes. A metodologia aplicada foi dados em painel dinâmico de dois estágios com estimador de GMM sistêmico. Os resultados encontrados pelo modelo de regressão sugeriram que os CEO's tendem a imprimir seu estilo de gestão, uma vez que o "curso de graduação" foi a variável mais significativa, demonstrando que CEO's com curso de graduação na área de exatas (engenharias) e na área de negócios (contabilidade, economia e administração) apresentaram maior alavancagem no longo prazo.

Palavras-chave: Características dos CEO's. Estrutura de Capital. Determinantes. IBrX-100 BM\&FBOVESPA. Alavancagem de Longo Prazo.

\section{ABSTRACT}

Based on theoretical assumptions used by agency models regarding the relationship between capital structure and CEO's management style, the aim of this paper is to analyze the influence of CEO's individual characteristics such as: age, gender, tenure, family relationships, type of remuneration and undergraduate degree, on the capital structure of the companies listed in the IBrX-100 index of BM\&FBOVESPA during the period between 2009 to 2013, while keeping constant the factors related to the firm characteristics. The methodology used was a two-stage dynamic panel data model estimated by systemic GMM parameters. The results suggest that CEO's tend to express their management style since "undergraduate degree" was the most statistically significant variable, indicating that CEO's with undergraduate studies in exact sciences (engineering) and business related degrees (accounting, economics and business administration) held greater leverage in the long run.

Keywords: CEO's characteristics. Capital structure. Determinants. IBrX-100 BM\&FBOVESPA. leverage in the long run.

Data de submissão: 17 de março de 2016.

Data de aprovação: 9 de setembro de 2016. 


\section{INTRODUÇÃO}

Nas evidências empíricas sobre estrutura de capital, as características do CEO (Chief Executive Officer) são consideradas como um efeito fixo que não varia ao longo do tempo (FRANK; GOYAL, 2007). No entanto, se as características dos CEO's, cargo administrativo mais elevado em uma organização, são diferentes e são eles os principais sujeitos responsáveis pela tomada de decisão corporativa (ADAMS; ALMEIDA; FERREIRA, 2005), por que não consider algumas de suas características nos modelos empíricos de análise sobre os determinantes da estrutura de capital?

Para Lemmon, Roberts e Zender (2008), ainda permanece desconhecido os principais fatores responsáveis pela explicação da maior parte da variação da estrutura de capital no longo prazo. As teorias da hierarquia de recursos e do trade-off estático e dinâmico explicam apenas parte dessas variações (GRAHAM; LEARY; ROBERTS, 2014), mas o paradigma ainda persiste.

Como alternativa complementar às principais teorias da estrutura de capital, as características dos CEO's despontam como variáveis determinantes do endividamento na medida em que incorpora o estilo de gestão adotado na empresa. Assim, a relevância de incluir esses fatores reside no pressuposto de que os CEO's são diferentes entre si e possuem qualidades, expertises e características divergentes que podem impactar, de acordo com o seu estilo de gestão, na forma como a empresa compõe o mix de recursos próprios e de terceiros, seja de maneira mais agressiva ou mais conservadora (BERTRAND; SCHOAR, 2003; FRANK; GOYAL, 2007; MALMENDIER; TATE, 2005; BEBER; FABBRI, 2012; CRONQVIST; MAKHIJA; YONKER, 2012; YIM, 2013).

Diante o exposto, o problema de pesquisa proposto é: as características dos CEO's influenciam na estrutura de capital de empresas brasileiras? Para tentar responder ao problema de pesquisa apresentado, o objetivo deste artigo é analisar quais características individuais de CEO's quanto à idade, sexo, tempo de mandato na empresa, presença de relação familiar, tipo de remuneração e curso de graduação influenciam na estrutura de capital corporativa das empresas listadas no IBrX-100 da BM\&FBOVESPA no período de 2009 a 2013, mantendo os fatores no nível da firma constantes.

A contribuição deste artigo reside na incorporação de atributos pessoais dos CEO's na geração de valor da firma por meio da estrutura de capital, principalmente no longo prazo. Essa pressuposição baseia-se na visão tradicional das Finanças Corporativas de que a estrutura de capital gera valor para a empresa ao longo do tempo (DURAND, 1952). Desse modo, pretende-se contribuir com a literatura teórica e empírica sobre estrutura de capital no Brasil ao incluir o estilo de gestão dos CEO's como determinante relevante para a composição do endividamento, conforme sugerem alguns trabalhos internacionais (BERTRAND; SCHOAR, 2003; FRANK; GOYAL, 2007; MALMENDIER; TATE, 2005; BEBER; FABBRI, 2012; CRONQVIST; MAKHIJA; YONKER, 2012; YIM, 2013; CUSTÓDIO; METZGER, 2014) e nacionais (BARROS; SILVEIRA, 2008).

Este artigo está formatado, em suplementação à presente introdução, em mais 5 seções: as duas primeiras seções referem-se ao referencial teórico, abordando sobre a visão neoclássica e os modelos de agência, seguida pela apresentação das principais evidências empíricas do tema. Na seção 4 a metodologia é descrita e na seção 5 é desenvolvida a análise dos dados. Por fim, a seção 6 apresenta as considerações finais. 


\section{REFERENCIAL TEÓRICO: VISÃO NEOCLÁSSICA E MODELOS DE AGÊNCIA}

Desde os artigos bastante importantes sobre estrutura de capital desenvolvidos por Modigliani e Miller (1958; 1963 - MM), pesquisadores em Finanças Corporativas têm dedicado grande esforço em investigar os determinantes da estrutura de capital (CRONQVIST; MAKHIJA; YOUNKER, 2012). Durante o desenvolvimento do tema, incremental em relação a $\mathrm{MM}$, o direcionamento das pesquisas acerca dos fatores determinantes da estrutura de capital tem focado em diferentes fatores que possam influenciá-la, dentre eles as características do CEO.

Recentemente, percebe-se que um tema recorrente em pesquisas empíricas aborda sobre a influência das características pessoais do CEO na estrutura de capital corporativa, mantendo os fatores no nível da firma constantes (BERTRAND; SCHOAR, 2003). Essa alternativa teórica surge devido à insuficiência da pecking order theory e da static ou dynamic trade-off theories em explicar plenamente os fatores de primeira ordem associados às decisões do endividamento corporativo (FRANK; GOYAL, 2008).

Como essas duas principais teorias explicam parcialmente as variações da alavancagem (GRAHAM; LEARY; ROBERTS 2014), ainda permanece sem explicação empírica grande parte dessas variações no longo prazo (LEMMON; ROBERTS; ZENDER, 2008). Assim, uma alternativa que pode oferecer novas evidências para compreensão das decisões sobre a estrutura de capital corporativa é pelas características dos CEO's (BERTRAND; SCHOAR, 2003; FRANK; GOYAL, 2007; MALMENDIER; TATE, 2005; BEBER; FABBRI, 2012; CRONQVIST; MAKHIJA; YONKER, 2012).

No entanto, a relevância em considerar as características dos CEO's como determinantes da estrutura de capital é controversa. Há duas correntes teóricas divergentes que abordam sobre a influência dos CEO's na tomada de decisão e na geração de valor da firma.

De um lado, a visão neoclássica postula que os CEO's são homogêneos e substitutos perfeitos entre si, portanto suas características pessoais e estilo de gestão são irrelevantes nas decisões corporativas (BERTRAND; SCHOAR, 2003; BEBER; FABBI, 2012). De acordo com esses autores, essa pressuposição teórica é usualmente adotada nas pesquisas empíricas e pelas teorias clássicas em Finanças Corporativas.

A visão neoclássica defende que a influência individual exercida pelos CEO's na tomada de decisão é pequena e, consequentemente, pífia em relação ao volume de ativos transacionados pela empresa (BERTRAND; SCHOAR, 2003; FRANK; GOYAL, 2007). Desse modo, como as decisões corporativas são determinadas por fatores exógenos e orientadas à tecnologia e às condições de mercado dos produtos, então uma única pessoa não conseguiria interferir de forma significativa nesse contexto (BEBER; FABBRI, 2012).

Por outro lado, Jensen e Meckling (1976) comenta que a transformação de insumos em produtos não deve ser tratada como "caixas pretas" ou como puramente exógenas à firma, uma vez que existem conflitos de interesses entre principal-agente que são decorrentes desse relacionamento no interior da firma, gerando custos. Os principais direcionadores desses custos, denominados de custos de agência, são as informações assimétricas, comportamento oportunista dos CEO's e os mecanismos de controle e monitoramento impostos pelos proprietários da firma aos agentes (MALMENDIER; TATE, 2005; YIM, 2013).

A descrição desse cenário apresenta o contexto em que se insere a relevância das características dos CEO's na estrutura de capital corporativa. Com base nos modelos de agência, essa corrente teórica 
postula que características dos CEO's que maximizam o desempenho corporativo são desejáveis quando os interesses entre principal-agente estão alinhados (BERTRAND; SCHOAR, 2003). Insere-se também nessa questão o fato de que o CEO é o maior posto em uma hierarquia organizacional, portanto seus atributos podem interferir na tomada de decisão, indicando, inclusive, que suas características podem delinear um estilo de gestão (BEBER; FABBI, 2012).

No artigo seminal sobre o tema, Bertrand e Schoar (2003) discutem duas possíveis consequências de como o poder de discricionariedade dos CEO's podem alterar as decisões corporativas a depender dos mecanismos de governança. Analogamente, Beber e Fabbri (2012) argumentam que os modelos de agência propõem que as variações do comportamento corporativo quanto ao poder de discricionariedade do CEO dependem da heterogeneidade e intensidade dos mecanismos de governança.

Por exemplo, quando a governança é falha e os controles sobre os CEO's são ineficientes, esses, por sua vez, conseguem impor suas preferências, aversão ao risco e crenças pessoais nas decisões corporativas de modo a beneficiá-lo; alternativamente, se as características anteriores dos CEO's oferecem um melhor desempenho para a organização e os mecanismos de governança e os de controles são fortes e eficientes, elas se tornam desejáveis (BERTRAND; SCHOAR, 2003; CRONQVIST; MAKHIJA; YONKER, 2012). Ou seja, no primeiro caso as características dos CEO's podem conduzir à tomada de decisão subótima, uma vez que permite o comportamento oportunista do CEO. O segundo caso, no entanto, demonstra que quando o estilo de gestão individual do CEO maximiza os interesses da organização, há o incentivo e motivação pelo Conselho de Administração em contratar um gestor com esse perfil para alinhá-lo à estratégia corporativa adotada (BERTRAND; SCHOAR, 2003; FRANK; GOYAL, 2007; CRONQVIST; MAKHIJA; YONKER, 2012; BEBER; FABBRI, 2012).

Nesse sentido, torna-se importante evidenciar a relevância que o CEO desempenha nas decisões estratégicas das empresas (PAPADAKIS; BARWISE, 2002), principalmente na forma como isso pode influenciar a geração de valor corporativo por meio da estrutura de capital. Sobre isso, Bertrand e Schoar (2003) comentam que os gestores se diferem de acordo com suas percepções de vantagem competitiva ou em relação às suas habilidades, uma vez que as empresas escolhem de forma ótima os CEO's que se adéquam às necessidades da estratégia adotada. Assim, as autoras afirmam que não existe estilo "bom" ou "ruim" de gestão, e sim estilos de gestão que se moldam melhor aos diferentes ambientes de tomada de decisão.

Consistente com o que preconiza os modelos de agência em relação ao CEO, a corrente teórica da Visão Baseada em Recurso (RBV - resource-based view) também reconhece a relevância de incorporar os atributos individuais dos CEO's na tomada de decisão corporativa. Na RBV, admite-se que a heterogeneidade de recursos, competências e capacidades internas da firma podem ser compreendidas como um diferencial superior e distintivo em relação aos seus concorrentes, constituindo em vantagem competitiva sustentável (WERNERFELT, 1984; PETERAF, 1993).

De acordo com essa visão, os CEO's fazem parte dos recursos estratégicos diferenciais, superiores e distintivos da organização, uma vez que eles influenciam o direcionamento estratégico da firma (ROTEMBERG; SALONER, 2000). A RBV considera, portanto, que o alinhamento do perfil do CEO com a estratégia da firma constitui, de acordo com a classificação de Barney (1991), em um recurso valioso, raro, insubstituível e original. 
É importante, todavia, destacar a diferença entre a visão da Estratégia, com base na RBV, da visão de Finanças Corporativas, com base nos modelos de agência. Enquanto que a primeira possui maior ênfase em competências e valores idiossincráticos dos CEO's, em Finanças a ênfase reside nas características identificáveis e compartilhadas entre CEO's. Como exemplo de tais características, pode-se citar: idade, tempo de mandato, formação acadêmica, religião, turnover, endividamento pessoal, etc.

\section{EVIDÊNCIAS EMPÍRICAS}

Evidências empíricas apontam que características observáveis do CEO como religião (HILARY; HUI, 2008), idade (YIM, 2013; SERFLING, 2014), tipo de remuneração recebida (CORE, HOLTHAUSEN, LARCKER, 1999; BENMELECH, KANDEL, VERONESI, 2010) e o grau de instrução adquirido (TERRANCE, RAMESH, MERCEDES, 2002; BHAGAT, BOLTON, SUBRAMANIAN, 2010) podem influenciar no desempenho de empresas estadunidenses. Especificamente, essas características influenciam diretamente nas variações do endividamento corporativo.

No artigo seminal sobre a influência do estilo de tomada de decisão dos gestores em relação às políticas de investimento, financiamento, estratégia organizacional e de desempenho, Bertrand e Schoar (2003) encontraram que os efeitos fixos relacionados à gestão são determinantes empiricamente importantes. Especificamente para a estrutura de capital, Bertrand e Schoar (2003) evidenciaram que ao incluir o efeito fixo do estilo da gestão, o grau de ajustamento da regressão foi maior. Além disso, as autoras evidenciaram que os gestores se diferenciam em relação à agressividade ou ao conservadorismo de suas decisões financeiras: ceteris paribus, alguns gestores preferem manter menores níveis de endividamento e maiores valores em caixa, principalmente quando os CEO's são mais velhos; no entanto ter MBA não foi irrelevante.

Frank e Goyal (2007) analisaram a relevância do comportamento de CEO's na estrutura de capital. Para isso, os autores observaram a influência das demissões rotineiras e forçadas, assim como as características dos CEO's na escolha da alavancagem corporativa. Os achados dessa pesquisa demonstraram que a inclusão de efeitos fixos relacionado às características dos CEO's também melhoraram o grau de ajustamento da regressão, inclusive para os modelos dinâmicos, e que CEO's demitidos forçadamente mantiveram a alavancagem acima do normal devido à fraca performance. Em relação às características dos CEO's, os autores evidenciaram que quanto maior o tempo de mandato, menor a alavancagem, e os CEO's com MBA mantinham maiores índices de alavancagem e maior rapidez no ajustamento do nível de endividamento.

Utilizando como referencial teórico o comportamento consistente das decisões na esfera pessoal em relação à esfera do trabalho, Cronqvist, Makhija e Yonker (2012) evidenciaram que CEO's que possuem maior endividamento pessoal refletem isso na escolha de um maior nível de alavancagem das empresas que gerenciam. Desse modo, os CEO's imprimem suas preferências pessoais na tomada de decisão do endividamento, principalmente quando a governança corporativa é fraca. Assim, os autores concluem que o comportamento do CEO pode contribuir para a compreensão da composição da estrutura de capital corporativa.

Custódio e Metzger (2014) demonstraram que CEO's que são expert em finanças, isto é, possuem experiências anteriores na área de Finanças, mantêm menores saldos em caixa, maiores índices de 
endividamento, apresentam maior propensão ao pagamento de dividendos e a estrutura financeira da empresa é mais sofisticada. Os autores encontraram também que esses CEO's possuem melhor acesso ao mercado de capitais. Resultados similares também foram encontrados por Mishra (2014).

No Brasil, apesar de evidências empíricas ainda incipientes, Barros e Silveira (2008) delinearam uma abordagem comportamental por meio de vieses cognitivos, tais como o otimismo e excesso de confiança, para compreensão dos determinantes da estrutura de capital. Por meio de uma regressão por dados em painel dinâmico, os autores encontraram que o índice que capturou o excesso de confiança e o otimismo gerencial despontou como variável determinante e significativa estatisticamente para o endividamento corporativo, admitindo como variáveis de controle os determinantes da estrutura de capital que são usualmente adotados em pesquisas empíricas.

\section{METODOLOGIA}

Utilizou-se como amostra empresas não financeiras que permaneceram listadas no índice IBrX-100 da BM\&FBOVESPA durante o período de 2009 a 2013, totalizando 57 empresas. A periodicidade deses dados é anual, sendo o ano de 2008 incluído com o objetivo de servir de base para calcular a alavancagem defasada.

O delineamento amostral adotado justifica-se pela liquidez apresentada pelas empresas do IBrX100 no mercado acionário brasileiro, contribuindo principalmente para o cálculo de variáveis que utilizam dados de mercado (por exemplo, o Market-to-book). Em relação ao período abrangido, a escolha deve-se às mudanças das normas brasileiras de contabilidade e em relação à disponibilidade de dados em demonstrativos financeiros sobre as características dos CEO's.

Para coletar as variáveis determinantes do endividamento foi utilizado o Economática ${ }^{\circledR}$, enquanto que para as variáveis relacionadas às características dos CEO's a coleta procedeu-se de forma manual, sendo a principal fonte de dados os Relatórios de Referência disponíveis no sítio eletrônico da BM\&FBOVESPA. Considerou-se como CEO o cargo de Diretor Presidente, descrição adotada nesses relatórios. Foram excluídas da amostra empresas que: apresentaram patrimônio líquido negativo; estavam passando por processos de falência; não apresentaram todos os dados necessários; e apresentaram alavancagem maior do que 1.

Em consequência da presença de autocorrelação nos resíduos no primeiro momento e de possíveis problemas de endogeneidade entre a variável dependente e seus regressores, comuns aos estudos de estrutura de capital (BARROS; SILVEIRA, 2008), o modelo de dados em painel dinâmico com estimador GMM (generalized method of moments) sistêmico de dois estágios proposto por Arellano e Bover (1995) e Blundell e Bond (1998), corrigido por Windmeijer (2005), foi escolhido para estimar a regressão da equação [1]. A motivação em utilizar esse modelo econométrico deve-se à sua capacidade de estimar parâmetros robustos ao considerar os problemas ora apresentados (BALTAGI, 2008).

O modelo de dados em painel dinâmico com estimador de GMM sistêmico, por ser endógeno por construção, incorpora a variável dependente defasada entre as variáveis independentes. Baltagi (2008) explica que esse modelo é indicado para uma melhor compreensão das dinâmicas de ajustamento e para atender alguns problemas de endogeneidade. Nessa pesquisa, outra motivação para utilizar o modelo de dados em painel dinâmico decorre da teoria do trade-off, cuja uma das suas principais previsões teóricas é 
de que as empresas procuram, em média, perseguir um endividamento ótimo, porém, em consequência de imperfeições de mercado e de decisões corporativas, oscilações ocorrem, podendo ser esse comportamento capturado pela variável dependente defasada entre os regressores (BÓGEA SOBRINHO; SHENG; LORA, 2012). A notação geral da equação do modelo e das variáveis pesquisadas está demonstrado na equação 1.

$$
A L A V_{i t}=\alpha+\boldsymbol{\theta} A L A V_{t-1}+\beta^{\prime} \mathbf{X}_{i t}+\varepsilon_{i t}
$$

Em que: A variável dependente ALAV refere-se à alavancagem que divide-se em alavancagem total (soma dos passivos onerosos de curto prazo e de longo prazo), alavancagem de curto prazo e alavancagem de longo prazo; ALAV t-1 é a alavancagem (total, curto e longo prazo) defasada; $\mathbf{X}$ é a matriz de covariáveis explicativas que contém os determinantes do endividamento, especificamente a tangibilidade de ativos, tamanho da empresa, Market-to-book, lucratividade, escudos fiscais, singularidade e risco de falência, assim como abrange as características individuais do CEO quanto a idade e mandato, ambas em anos, e também dummies relacionadas à detenção do título de MBA, ao tipo de remuneração, à presença de relações familiares e ao curso de graduação obtido; $\alpha$ é o intercepto; $\varepsilon$ é o termo de erro aleatório composto (incorpora a heterogeneidade das firmas e dos anos); e os subscritos $i$ e $t$ referem-se a empresa e ano, de forma respectiva.

Deliberou-se que os determinantes da estrutura de capital baseiam-se nas teorias do pecking order e do trade-off. Conforme indicado na literatura, a inclusão dessas variáveis, consideradas como controle, tem por finalidade manter os fatores no nível da firma constantes, de modo a analisar especificamente os efeitos das características dos CEO's na estrutura de capital. Desse modo, as relações esperadas das variáveis de acordo com essas principais teorias da estrutura de capital estão apresentadas no Quadro 1.

\section{Quadro 1: Relação Esperada das variáveis determinantes do endividamento}

\begin{tabular}{|c|c|c|c|}
\hline Variável & Relação & Teoria & Fórmula \\
\hline Tangibilidade de ativos & Positiva & Trade-off & $\frac{\text { Ativo imobilizado }}{\text { Ativo total }}$ \\
\hline Tamanho & Positiva & Trade-off & In Ativo total \\
\hline Market-to-Book & Indefinido & $\begin{array}{l}\text { Trade-off e } \\
\text { Pecking Order }\end{array}$ & $\frac{\text { Valor contábil do patrimônio líquido }}{\text { Valor de mercado do patrimônio líquido }}$ \\
\hline Lucratividade & Negativo & Pecking Order & $\frac{\text { EBITDA }}{\text { Ativo total }}$ \\
\hline Risco de falência & Negativo & Trade-off & $\begin{array}{l}3,3 * \frac{E B I T}{\text { Ativo total }}+\frac{\text { Receita líquida }}{\text { Ativo total }}+1,4 * \\
\frac{\text { Reserva de lucros }}{\text { Ativo total }}+1,2 * \frac{\text { Ativo circulante }}{\text { Ativo total }}\end{array}$ \\
\hline Singularidade & Negativo & Trade-off & $\frac{\text { Ativo intangível }}{\text { Ativo total }}$ \\
\hline Escudo Fiscal & Negativo & Trade-off & $\frac{\text { Depreciação, amortização e exaustão }}{\text { Ativo total }}$ \\
\hline
\end{tabular}

Fonte: Elaborado pelos autores com base em Rajan e Zingales (1995); Perobelli e Famá (2002); Nakamura et al (2007); e em Rocha (2014). 
Espera-se uma relação positiva da tangibilidade de ativos e do tamanho da empresa de acordo com a teoria do trade-off, uma vez que são utilizadas como proxies para garantias de empréstimos e de melhor reputação, respectivamente (FRANK; GOYAL, 2008). Para esses autores, a expectativa de relacionamento negativo, ou inversamente proporcional, das proxies para risco de falência, singularidade e escudo fiscais também estão a favor da teoria do trade-off. Em relação ao risco de falência, espera-se que empresas mais arriscadas tendem a ter menor acesso ao capital de terceiros devido à maior probabilidade de falência, assim como empresas mais singulares, pois ativos intangíveis usualmente não são utilizados como garantias para empréstimos, enquanto que os escudos fiscais não decorrentes das dívidas demonstram que as empresas podem utilizar outras formas de dedução fiscal (PEROBELLI; FAMÁ, 2002; NAKAMURA ET AL, 2007; ROCHA, 2014).

A lucratividade, por sua vez, está em linha com a teoria do pecking order. Nessa teoria, é pressuposto que existe uma preferência pelas empresas em se financiar com recursos gerados internamente em detrimento aos recursos de terceiros (e, como último recurso, emissão de ações), portanto espera-se uma relação negativa (RAJAN; ZINGALES, 1995). A relação esperada para oportunidade de crescimento é controversa porque, do lado da teoria do trade-off, a relação esperada é negativa já que empresas em crescimento enfrentam maiores problemas de baixos investimentos e tendem a apresentar maior desvalorização quando vão à falência, enquanto que a teoria do pecking order espera uma relação positiva porque empresas em crescimento tendem a maximizar suas oportunidades de investimento já que dispõem de maior opções de investimentos lucrativos que podem empreender dado que o ambiente com o qual se encontra está favorável para isso (FRANK; GOYAL, 2008).

As variáveis dependentes utilizadas nesta pesquisa baseiam-se nas recomendações de Welch (2006; 2011) para calcular a alavancagem considerando apenas passivos onerosos em relação ao capital investido. A adequação dessa variável para o mercado acionário brasileiro foi verificada por Machado, Medeiros e Eid Júnior (2010).

Quadro 2: Variáveis Dependentes - Alavancagem Contábil

\begin{tabular}{|l|l|}
\hline Alavancagem Contábil & FÓRMULA \\
\hline $\begin{array}{l}\text { Alavancagem Total } \\
\text { (soma do curto e longo prazo) }\end{array}$ & $\begin{array}{l}\text { Empréstimos, Financiamentos e Debêntures de CP e LP divido } \\
\text { pelo capital investido. }\end{array}$ \\
\hline Alavancagem de Curto Prazo (CP) & $\begin{array}{l}\text { Empréstimos, Financiamentos e Debêntures de CP divido pelo } \\
\text { capital investido. }\end{array}$ \\
\hline Alavancagem de Longo Prazo (LP) & $\begin{array}{l}\text { Empréstimos, Financiamentos e Debêntures de LP divido pelo } \\
\text { capital investido. }\end{array}$ \\
\hline
\end{tabular}

Fonte: Elaborado pelos autores com base em Welch (2006; 2011) e Machado, Medeiros e Eid Júnior (2010).

No tocante as variáveis determinantes da estrutura de capital que contemplam as características individuais do CEO, o Quadro 3 apresenta-as sucintamente. Tais variáveis proxy das características dos CEO's foram desenvolvidas com base nos artigos de Bertrand e Schoar (2003) e Frank e Goyal (2007). Concomitantemente, foi procedida uma análise em relação à disponibilidade desses dados para a amostra pesquisada. Após essa verificação, as variáveis finais que foram selecionadas nessa pesquisa estão descritas a seguir. 
Quadro 3: Relação Esperada das características do CEO’s

\begin{tabular}{|c|c|c|}
\hline Variável & FÓRMULA & Relação \\
\hline Idade [em anos] & Ln(idade) & Negativa \\
\hline Mandato [em anos] & Ln(mandato) & Negativa \\
\hline Remuneração fixa e variável & $\begin{array}{l}1 \text { = Fixa e Variável } \\
0=\text { Outros }\end{array}$ & Indefinida \\
\hline Remuneração por opções sobre ações & $\begin{array}{l}1=\operatorname{Sim} \\
0=\text { Não }\end{array}$ & Indefinida \\
\hline Sexo & $\begin{array}{l}0=\text { homem } \\
1=\text { mulher }\end{array}$ & Indefinida \\
\hline Expertise (MBA) & $\begin{array}{l}1=\text { possui MBA } \\
0=\text { Não possui }\end{array}$ & Indefinida \\
\hline Graduação (N) negócio & $\begin{array}{l}1 \text { = Graduação em Cursos de negócio } \\
0=\text { Não possui Graduação em cursos de negócio }\end{array}$ & Indefinida \\
\hline Graduação (E) engenharias & $\begin{array}{l}1=\text { Graduação em Cursos de exatas } \\
0=\text { Não possui Graduação em cursos de exatas }\end{array}$ & Indefinida \\
\hline Graduação (O) outras & $\begin{array}{l}1=\text { outras graduações e } \\
0=\text { não possui outras graduações }\end{array}$ & Indefinida \\
\hline Relações Familiares & $\begin{array}{l}1=\operatorname{Sim} \\
0=\text { Não }\end{array}$ & Indefinida \\
\hline
\end{tabular}

Fonte: Elaborado pelos autores.

O tipo de remuneração, sexo, graduação, MBA e relações familiares têm sinais esperados indefinidos de acordo com as evidências empíricas consultadas. A idade e o mandato, por outro lado, são usualmente utilizadas como proxies comportamentais para o CEO e tem o sinal negativo como relação esperada.

Esse relacionamento inversamente proporcional é esperado por essas duas variáveis porque CEO's mais velhos e com maior tempo de mandato na empresa tendem a apresentar um estilo de gestão mais conservador e exibem maior aversão ao risco, evitando, assim, incorrer em dívidas devido aos seguintes fatores: não aumentar o nível de risco da empresa; satisfazer os interesses dos proprietários com a remuneração por meio de fluxos de caixa livres para agradá-los e, assim, manter-se no emprego; vivência em períodos de grande instabilidade econômica, denominado na literatura como "depression babies" (BERTRAND; SCHOAR, 2003; YANG; ZIMMERMAN; JIANG, 2011; CRONQVIST; MAKHIJA; YONKER, 2012; BEBER; FABBRI, 2012; AMRAN, 2014). 


\section{ANÁLISE DE RESULTADOS}

A análise exploratória dos dados, que enfatizou as interpretações em torno da média dos valores reportados pelas variáveis pesquisadas, foi iniciada com a estatística descritiva, conforme reporta a Tabela 1. Ressalta-se que 57 empresas compuseram a amostra e que o total de observações foi de 285.

Tabela 1: Estatística Descritiva da amostra

\begin{tabular}{lrrrrrrr}
\hline Variável & \multicolumn{1}{c}{ Média } & Desvio-Padrão & Mínimo & Máximo & $\mathbf{1}^{\circ} \mathbf{Q u a r t i l}$ & $\mathbf{2}^{\circ} \mathbf{Q u a r t i l}$ & $\mathbf{3}^{\circ} \mathbf{Q u a r t i l}$ \\
\hline Alavancagem & 0,4653 & 0,2083 & 0,010 & 1,000 & 0,330 & 0,440 & 0,610 \\
Alavancagem CP & 0,1076 & 0,0821 & 0,000 & 0,427 & 0,049 & 0,085 & 0,148 \\
Alavancagem LP & 0,3459 & 0,1713 & 0,000 & 0,825 & 0,234 & 0,332 & 0,451 \\
Tangibilidade & 0,2974 & 0,2974 & 0,000 & 0,899 & 0,048 & 0,295 & 0,434 \\
Tamanho & 16,5363 & 1,1328 & 12,870 & 20,440 & 15,860 & 16,460 & 17,160 \\
Market-to-book & 3,8966 & 4,4198 & 0,552 & 32,304 & 1,575 & 2,445 & 4,116 \\
Lucratividade & 0,1304 & 0,0961 & $-0,104$ & 0,560 & 0,072 & 0,107 & 0,173 \\
Risco & 1,3311 & 1,1218 & 0,040 & 8,580 & 0,790 & 1,080 & 1,510 \\
Escudo Fiscal & 0,0302 & 0,0172 & 0,002 & 0,069 & 0,021 & 0,029 & 0,039 \\
Singularidade & 0,0831 & 0,1509 & 0,000 & 0,550 & 0,000 & 0,007 & 0,089 \\
Idade & 53,6877 & 9,1473 & 33 & 76 & 47 & 54 & 60 \\
Mandato & 11,4070 & 10,6343 & 1 & 45 & 4 & 7 & 16 \\
\hline
\end{tabular}

Fonte: Elaborada pelos autores.

Na Tabela 1 é verificado que as empresas do IBrX-100, período de 2009 a 2013, se financiaram $46 \%$ com passivos onerosos (alavancagem total), sendo a maior parte deles por meio de passivos onerosos de longo prazo. A lucratividade das empresas representa $12 \%$ dos ativos totais. Os ativos tangíveis representam aproximadamente $29 \%$ do volume médio dos ativos, com grandes variações em empresas tangível-intensivas ( $3^{\circ}$ quartil) em relação a empresas pouco tangível-intensivas, conforme pode ser observado pelo $1^{\circ}$ quartil, assim como por meio do desvio-padrão apresentado por essa variável.

O tamanho médio das empresas se aproxima da mediana, apresentando pouca variação ao longo de sua distribuição. As variáveis "Risco de Falência" e "Market-to-Book", por outro lado, apresentam grande variação de acordo com a diferença exibida pelos valores de mínimo e máximo e pelas distâncias entre o $1^{\circ}$ e o $3^{\circ}$ quartil. Os menores coeficientes médios foram apresentados pelos ativos intangíveis, que representam, em média, $8 \%$ do volume total de ativos, e os escudos fiscais, que representam em torno de $3 \%$.

As características dos gestores em relação à idade e tempo de atuação na empresa (mandato) estão representadas em anos. O objetivo de exibi-las dessa forma foi para facilitar a compreensão do comportamento dos dados amostrais, uma vez que em logaritmo natural a interpretação seria pouco intuitiva.

A Tabela 1 mostra que a idade média dos CEO's é de 53 anos, sendo o mais novo com 33 e o mais velho com 76 anos. Já a duração média dos mandatos desses CEO's é de 11 anos. Logo, é possível deduzir que, em média, os CEO's pesquisados nasceram por volta da década de 60 , isto é, cresceram durante a ditadura militar e vivenciaram, na idade adulta, períodos de alta inflação e instabilidade econômica no Brasil 
durante as décadas de 80 e 90. Além disso, eles possuem experiência média de mais de 10 anos na mesma organização.

O delineamento das possíveis experiências vivenciadas pelos CEO's em cenários macroeconômicos pessimistas é conhecido na literatura internacional por "depression babies" (CRONQVIST; MAKHIJA; YONKER, 2012). Para esses autores, essa geração de "depression babies" tem fortes inclinações ao conservadorismo na tomada de decisão corporativa uma vez que sua aversão ao risco é influenciada pelas experiências econômicas negativas com as quais cresceram.

A apresentação da distribuição de frequência das variáveis não-métricas relacionadas com as características dos CEO's está sumarizada na Tabela 2. Como são variáveis binárias, foi especificado o sexo, tipo de formação e remuneração em duas opções: "sim", para os valores iguais a um, e em "não" para valores iguais a zero.

Tabela 2: Descrição da frequência de variáveis dummies

\begin{tabular}{l|r|r|r|l}
\hline Variáveis & \multicolumn{1}{c|}{ Sim } & \multicolumn{1}{c|}{$\%$} & \multicolumn{1}{c|}{ Não } & \multicolumn{1}{c}{$\%$} \\
\hline MBA & 137 & $48 \%$ & 148 & $52 \%$ \\
\hline Relações Familiares & 28 & $10 \%$ & 257 & $90 \%$ \\
\hline Formação em Engenharia & 144 & $42 \%$ & 198 & $58 \%$ \\
\hline Formação em Negócios & 109 & $32 \%$ & 233 & $68 \%$ \\
\hline Sexo: Homens & 269 & $95 \%$ & 15 & $5 \%$ \\
\hline Remuneração: Fixa e Variável & 285 & $100 \%$ & 0 & $0 \%$ \\
\hline
\end{tabular}

Fonte: Elaborada pelos autores

A Tabela 2 exibe que 100\% dos CEO's possuem remuneração fixa e variável, e a presença de relações familiares dos CEO's com outros membros da empresa foi de apenas $9 \%$. O sexo dos CEO's é outra variável com pouca alteração: 95\% são homens. Dessa forma, pode-se inferir que mais de 90\% dos CEO's pesquisados são homens, possui poucas relações familiares dentro da organização e recebem remuneração fixa e variável. Como consequência da pouca variabilidade dessas variáveis, optou-se por excluí-las na análise da regressão.

A formação acadêmica dos CEO's foi dividida em duas áreas: exatas e negócios. Considerou-se a graduação em cursos de engenharia como pertencentes à área de exatas, ao passo que foi considerado como negócios os cursos de Administração, Economia e Contábeis. Os CEO's que não tinham nenhuma dessas formações foram considerados como "outros" e formaram o grupo base na regressão. Assim, cerca de $42 \%$ dos CEO's possuem graduação em engenharia e 32\% em cursos na área de negócios.

No tocante à expertise, a Tabela 2 evidencia que os CEO's com título de pós-graduação fornecido por cursos de MBA representam 49\% da amostra. Ou seja, 51\% dos CEO's não possuem expertise certificada por cursos de MBA.

A continuação da investigação exploratória dos dados está exibida na Tabela 3, que apresenta a matriz de correlação de Pairwise entre as variáveis métricas, apresentando o coeficiente da correlação, bem como seu nível de significância. A ênfase da análise desenvolvida foi dada pela primeira, segunda e terceira coluna que relaciona as correlações entre as variáveis dependentes e as independentes pesquisadas. 


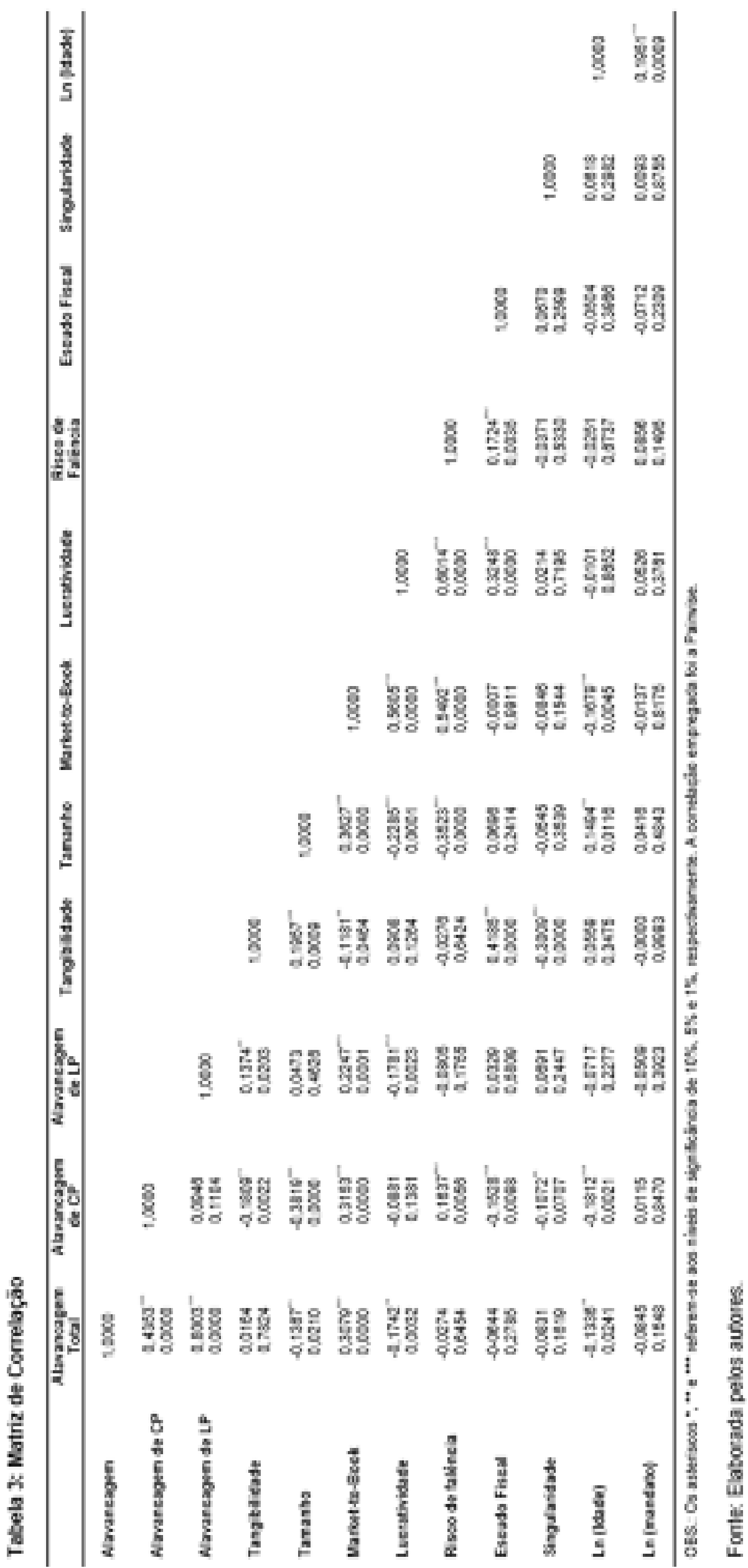


De acordo com a Tabela 3, a idade do CEO possui correlação negativa e significativa estatisticamente com a alavancagem, conforme prevê a orientação teórica do Quadro 3: Dessa forma, sugerese que CEO's mais velhos podem ser mais conservadores. Ressalta-se que a variação inversamente proporcional ocorreu na alavancagem total e de curto prazo. Já o tempo de mandato na empresa não foi significativo em relação ao endividamento total, de curto e longo prazos.

As variáveis "Tangibilidade", "Risco de Falência", "Tamanho", "Singularidade" e "Escudo Fiscal" apresentaram variações com sinais contraditórios para a alavancagem total, de curto prazo e de longo prazo, principalmente quando comparados com as previsões teóricas. Por outro lado, as variáveis "Market-to-Book" e "Lucratividade" foram mais consistentes e apresentaram correlações direta e inversamente proporcionais, respectivamente.

Ao analisar os coeficientes de correlação indicados na Tabela 3, nota-se que foram inferiores a 0.6, o que pode ser um indicativo de ausência de multicolinearidade. A exceção disso ocorreu entre alavancagem total com a alavancagem de longo prazo, contudo ambas não foram incluídas na mesma regressão. As variáveis com correlação mais próximas a 0.6 foram entre "Risco de Falência" e "Lucratividade", "Risco de Falência" e "Market-to-Book", e "Lucratividade" e "Market-to-Book".

A Tabela 4 apresenta a estimação das regressões por dados em painel dinâmico com estimador de GMM sistêmico de dois estágios. Ressalta-se que cada coluna representa uma estimação da alavancagem: a variável dependente da primeira coluna é a alavancagem total, a segunda coluna é a alavancagem de curto prazo e a terceira é a alavancagem de longo prazo.

Os resultados encontrados na Tabela 4 indicam que a alavancagem defasada foi significativa e positiva nas três estimações para a alavancagem, sugerindo a existência de custos de transação para ajustar a estrutura de capital de volta ao seu ponto ótimo quando desvios ocorrem, o que retarda o processo de ajuste, assim como verificado em Correa, Basso e Nakamura (2013). O maior coeficiente da alavancagem defasada foi apresentado pela alavancagem de longo prazo.

Os determinantes da estrutura de capital possuem relações ambíguas. Para a alavancagem de curto prazo, apenas o Market-to-Book foi significativo estatisticamente. Esse resultado, no entanto, não é contraditório uma vez que é pressuposto que as relações esperadas pelos determinantes da estrutura de capital pautam-se na realidade americana, em que os passivos de longo prazo são mais expressivos e a geração de valor por meio da estrutura de capital ocorrem também no longo prazo. A tabela 4 apresenta os resultados das regressões realizadas para as três variáveis dependentes definidas no presente estudo. 
Tabela 4: Resultados das regressões

\begin{tabular}{|c|c|c|c|}
\hline Variável & Alavancagem & Alavancagem CP & Alavancagem LP \\
\hline Alavancagem $\mathrm{t}_{\mathrm{t}-1}$ & $\begin{array}{l}0,4389^{*} \\
0,0650\end{array}$ & ---- & ----- \\
\hline Passivo Oneroso $\mathrm{CP}_{\mathrm{t}-1}$ & ----- & $\begin{array}{l}0,352^{* * *} \\
0,008\end{array}$ & ---- \\
\hline Passivo Oneroso LP $\mathrm{t}_{\mathrm{t}-1}$ & ---- & ----- & $\begin{array}{l}0,769^{* \star *} \\
0,000\end{array}$ \\
\hline Tangibilidade & $\begin{array}{c}-0,095 \\
0,470\end{array}$ & $\begin{array}{l}0,086 \\
0,231\end{array}$ & $\begin{array}{l}0,220^{* *} \\
0,076\end{array}$ \\
\hline Tamanho & $\begin{array}{l}0,128^{* *} \\
0,004\end{array}$ & $\begin{array}{c}-0,029 \\
0,478\end{array}$ & $\begin{array}{l}0,049 \\
0,315\end{array}$ \\
\hline Market-to-book & $\begin{array}{l}0,026^{* * *} \\
0,000\end{array}$ & $\begin{array}{l}0,010^{* *} \\
0,026\end{array}$ & $\begin{array}{l}0,014^{* *} \\
0,085\end{array}$ \\
\hline Lucratividade & $\begin{array}{r}-0,073 \\
0,806\end{array}$ & $\begin{array}{l}0,217 \\
0,554\end{array}$ & $\begin{array}{c}-0,568^{* *} \\
0,013\end{array}$ \\
\hline Risco de falência & $\begin{array}{r}-0,002 \\
0,961\end{array}$ & $\begin{array}{r}-0,087 \\
0,150\end{array}$ & $\begin{array}{l}0,014 \\
0,839\end{array}$ \\
\hline Escudo Fiscal & $\begin{array}{l}0,272 \\
0,692\end{array}$ & $\begin{array}{l}0,268 \\
0,555\end{array}$ & $\begin{array}{c}-2,415^{\star *} \\
0,027\end{array}$ \\
\hline Singularidade & $\begin{array}{r}-0,228 \\
0,109\end{array}$ & $\begin{array}{r}-0,056 \\
0,496\end{array}$ & $\begin{array}{r}-0,078 \\
0,608\end{array}$ \\
\hline Ln(idade) & $\begin{array}{r}-0,001 \\
0,989\end{array}$ & $\begin{array}{l}0,001 \\
0,993\end{array}$ & $\begin{array}{l}0,061 \\
0,647\end{array}$ \\
\hline Engenheiro & $\begin{array}{l}0,007 \\
0,852\end{array}$ & $\begin{array}{l}0,013 \\
0,742\end{array}$ & $\begin{array}{l}0,091^{\star *} \\
0,005\end{array}$ \\
\hline Negócios & $\begin{array}{l}0,049^{* *} \\
0,039\end{array}$ & $\begin{array}{l}0,012 \\
0,793\end{array}$ & $\begin{array}{l}0,076^{* *} \\
0,036\end{array}$ \\
\hline MBA & $\begin{array}{l}0,022 \\
0,289\end{array}$ & $\begin{array}{l}0,009 \\
0,563\end{array}$ & $\begin{array}{l}0,036 \\
0,185\end{array}$ \\
\hline Constante & $\begin{array}{c}-1,960^{\star *} \\
0,018\end{array}$ & $\begin{array}{r}-0,542 \\
0,437\end{array}$ & $\begin{array}{r}-1,053 \\
0,270\end{array}$ \\
\hline
\end{tabular}

OBS.: Ressalta-se que os asteriscos ${ }^{*},{ }^{* *} \mathrm{e}^{* \star *}$ referem-se aos níveis de significância de $10 \%, 5 \%$ e $1 \%$, respectivamente. Nas três estimações para alavancagem, o teste de Wald indicou que a relevância conjunta das variáveis é significativa a 1\%. Em todas as regressões estimadas, o teste de Sargan indicou que os instrumentos são válidos (alavancagem defasada) e o teste de Arellano-Bond indicaram autocorrelação no primeiro momento e ausência de autocorrelação no segundo momento. Os erros-padrão são robustos a heterocedasticidade. As variáveis "Tamanho, Tangibilidade, Singularidade, Market-to-Book, Escudo Fiscal, Lucratividade e Risco" foram winsorizadas a $10 \%$. A estrutura dos dados é balanceada e a série temporal dos dados em painel desta pesquisa é estacionária de acordo com o teste de Levin-Liu-Chu. A variável In(mandato) foi retirada porque não apresentou significância estatística na matriz de correlação e nem na regressão.

Fonte: Elaborada pelos autores

Analisando a Tabela 4, verifica-se que as estimações mais consistentes estatisticamente ocorreram na alavancagem de longo prazo. Desse modo, verificou-se que os fatores determinantes da estrutura de mais comuns aos estudos do tema, conforme pontuado por Frank e Goyal (2009) e por Rajan e Zingales (1995), também puderam ser parcialmente identificados parcialmente no Brasil, principalmente para alavancagem de longo prazo.

Em relação às características individuais dos CEO's, a Tabela 4 mostra que apenas a graduação foi significativa para a estrutura de capital, principalmente para os CEO's graduados em cursos na área de negócios. De acordo com os resultados encontrados, CEO's que pressupõem-se deter maior conhecimento estatístico (a exemplo daqueles promovidos pelos cursos de graduação em exatas) e de gestão 
(proporcionados pelos cursos na área de negócios) são mais arrojados no longo prazo. Essa característica sugere que os CEO's das empresas compreendidas na amostra pesquisada tendem a delinear um estilo da gestão mais agressivo, ou seja, com maior proporção de capital de terceiros em sua estrutura de capital. Esse resultado foi encontrado por meio da relação positiva estimada entre as variáveis "engenheiro" e "negócios", consideradas como duas características do CEO's, e a alavancagem corporativa.

De acordo com a literatura do tema, sugere-se que esse comportamento, que em um primeiro momento pode ser compreendido como de maior risco, pode estar respaldado no maior conhecimento que esses CEO's possuem para embasar suas decisões por meio da maximização de recursos de capital de terceiros no financiamento corporativo. Isso, de acordo com Bertrand e Schoar (2003), Frank e Goyal (2007), Cronqvist, Makhija e Yonker, (2012) e Beber e Fabbri (2012), se torna desejável para a organização quando os interesses do principal e do agente, neste caso acionistas e CEO's, respectivamente, estão alinhados, assim como quando os mecanismos de governança corporativa são fortes. Resultados similares foram encontrados em Terrance, Ramesh e Mercedes (2002); Frank e Goyal (2007); e Bhagat, Bolton e Subramanian (2010).

Nesse sentido, o resultado encontrado sugere que a graduação do CEO pode influenciar no modo como sua decisão sobre a estrutura de capital corporativa pode ser construída. No ponto de vista financeiro, uma empresa que possui maior volume de capital de terceiros em sua estrutura de financiamento não necessariamente sinaliza uma má gestão de recursos ou insuficiência financeira. Para detectar isso, estudos sobre probabilidade de falência, liquidez financeira e performance corporativa devem ser desenvolvidos, o que escapa do escopo desta pesquisa. Aqui, o ponto fundamental é compreender que existe relações positivas entre a alavancagem da empresa e a graduação do CEO, de modo que há um indicativo de que os CEO's de companhias brasileiras, assim como verificado em evidências empíricas internacionais, tendem a imprimir seu estilo de gestão nas companhias que administram, mantendo os fatores no nível das firmas constantes (a exemplo dos determinantes da estrutura de capital).

Em Barros e Silveira (2008), a relação positiva encontrada entre alavancagem (contábil e de mercado) e a proxy construída para vieses cognitivos (excesso de confiança e otimismo gerencial) também foi positiva, indicando que os gestores com características otimistas tendem a compor uma estrutura de capital com maior capital de terceiros nas empresas que administram. Na presente pesquisa, foi encontrado apenas que há relação positiva entre a graduação do CEO e a alavancagem corporativa. Por outro lado, ao contrário dos resultados indicados em evidências empíricas internacionais, a variável MBA não foi significativa estatisticamente em nenhuma das estimações realizadas.

Já com relação as variáveis de controle, a tangibilidade, o tamanho (apesar de não significativo), a lucratividade e o escudo fiscal estão de acordo com as previsões teóricas. Ou seja, no longo prazo os ativos fixos aumenta a capacidade de endividamento corporativo; já os recursos gerados internamente, medido pela lucratividade, apresentam relação negativa em virtude dessa fonte de recursos ser prioritária na hierarquia de financiamento; ao passo que o escudo fiscal, que apresentou maior coeficiente e foi negativo, constitui em um incentivo para que as empresas utilizem os benefícios fiscais por meio da vantagem proporcionada pela depreciação, exaustão e amortização. $\mathrm{Na}$ regressão estimada na Tabela 4 , o sinal esperado para as oportunidades de crescimento foi positivo e significativo. Assim, empresas que estão em fase de crescimento tendem a se endividar mais para financiar novos projetos de investimentos lucrativos, conforme a pecking 
order theory prevê, dado que as empresas se encontram em um ambiente favorável de negócios para empreender em novos projetos de investimentos que possuem retorno atrativos para os proprietários.

\section{CONSIDERAÇÕES FINAIS}

Seguindo uma literatura crescente que investiga a influência do estilo da gestão na composição da estrutura de capital corporativa, o objetivo dessa pesquisa foi analisar quais características individuais dos CEO's quanto à idade, sexo, tempo de mandato na empresa, presença de relação familiar, tipo de remuneração e curso de graduação influenciam na estrutura de capital das empresas listadas no $\mathrm{IBrX}-100$ da BM\&FBOVESPA no período de 2009 a 2013, mantendo os fatores no nível da firma constantes. A motivação em analisar essas características foi identificar se os CEO's de empresas brasileiras listadas no IBrX-100 imprimem seu estilo de gestão na composição do endividamento corporativo.

A metodologia utilizada para atingir a esse objetivo foi a análise de regressão por dados em painel dinâmico de dois estágios com estimador de GMM sistêmico. A escolha desse modelo deve-se a sua robustez para tratar problemas de endogeneidade, capturar efeitos dinâmicos e estimar parâmetros consistentes e não viesados quando há autocorrelação nos resíduos no primeiro momento (BALTAGI, 2008).

A análise da estatística descritiva demonstrou que a idade média dos CEO's é de 53 anos, o tempo de mandato médio é de 11 anos, e que 49\% dos CEO's possuem MBA, enquanto que $42 \%$ tem graduação em cursos de exatas e $32 \%$ na área de negócios. A matriz de correlação sugeriu que as variações entre idade e alavancagem são inversamente proporcionais e significativas estatisticamente, o que poderia indicar um comportamento de gestão conservador uma vez que CEO's mais velhos e que nasceram ou viveram em períodos de grande instabilidade econômica tendem a apresentar esse estilo de gestão. Entretanto, essa evidência inicial não indica causalidade, esta, por sua vez, pode ser estimada por meio da regressão.

A análise da regressão mostrou que a variável "idade" não foi significativa estatisticamente. Além disso, os resultados encontrados sugeriram que se pressupõe que CEO's com maior conhecimento estatístico (por meio de curso de graduação em exatas) ou na área de negócios (cursos de contabilidade, economia e administração) são mais arrojados no longo prazo, delineando um estilo de gestão mais agressivo por meio de um maior nível de endividamento no longo prazo. Verifica-se, portanto, que os CEO's das empresas analisadas tendem a imprimir seu estilo de gestão na estrutura de capital.

Em relação aos determinantes da estrutura de capital, os resultados indicaram que essas variáveis não são relevantes para a alavancagem de curto prazo, mas algumas se tornaram significativas para a alavancagem de longo prazo e total. Desse modo, essa pesquisa contribui para a literatura na medida em que evidencia a influência do estilo de gestão nas decisões corporativas, de modo a indicar um importante determinante da estrutura de capital em empresas brasileiras de capital aberto listadas no $\mathrm{IBrX}-100$ da BM\&FBOVESPA durante o período pesquisado, principalmente no longo prazo.

Os resultados reportados anteriormente possuem limitações. Dentre as características dos CEO's, foram retiradas da análise da regressão as variáveis "tempo de mandato", "presença de relação familiar" e "tipo de remuneração". A primeira foi retirada porque não foram encontradas significâncias estatísticas na matriz de correlação e na regressão. As duas últimas foram retiradas porque, conforme apontado pela estatística descritiva, ambas apresentaram pouca variação durante o período investigado. Desse modo, 
destaca-se que as contribuições descritas estão limitadas à amostra coletada, que impede a generalização dos resultados, ao curto período analisado, às variáveis proxy coletadas para características dos gestores e, também, ao método econométrico utilizado.

Dado que as contribuições desta pesquisa são incrementais à literatura sobre estrutura de capital em empresas listadas na BM\&FBOVESPA, bem como sua relação com as características com CEO's, recomenda-se alguns direcionamentos para pesquisas futuras. Nelas, sugere-se que um aumento da amostra, do período e das variáveis pesquisadas ou, ainda, que seja investigado possíveis relações entre as Finanças Comportamentais e estrutura de capital.

\section{REFERÊNCIAS}

ADAMS, Renee.; ALMEIDA, Heitor.; FERREIRA, Daniel. Powerful CEOs and their impact on Corporate Perfomance. The Review of Financial Studies, v. 18, n. 4, p. 1403-1432. 2005.

AMRAN, Noor. Do characteristics of CEO and Chairman influence government-linked companies performance?, Procedia-Social and Behavioral Sciences, v. 109, n. 2, pp.799-803.

ARELLANO, Manuel; BOVER, Olympia. Another look at the instrumental variable estimation of error-components models. Journal of Econometrics, v. 68, p. 29-51. 1995.

BALTAGI, Badi. Econometric analysis of panel data. John Wiley \& Sons. 2008.

BARNEY, Jay. Firm resources and sustained competitive advantage. Journal of Management, v. 17, n. 1, p. 99-120, 1991.

BARROS, Lucas.; SILVEIRA, Alexandre. Excesso de confiança, otimismo gerencial e os determinantes da estrutura de capital. Revista Brasileira de Finanças, v. 6, n. 3, p. 293-335, 2008.

BEBER, Alessandro.; FABBRI, Daniela. Who times the foreign exchange market? Corporate speculation and CEO characteristics. Journal of Corporate Finance, v. 18, p. 1065-1087, 2012.

BENMELECH, Efrain.; KANDEL, Eugene.; VERONESI, Pietro. Stock-based compensation and CEO (dis) incentives. The Quarterly Journal of Economics, v. 125, n.4, p. 1769-1820, 2010.

BERTRAND, Marianne.; SCHOAR, Antoinette. Managing with style: The effects of managers on firm policies. The Quarterly Journal of Economics, v. 118, n. 4, p. 1169-1208, 2003.

BHAGAT, Sanjai.; BOLTON, Brian.; SUBRAMANIAN, Ajay. CEO education, CEO turnover, and Firm Performance, Working paper, 2010. Disponível em < http://ssrn.com/abstract=1670219 >. Acesso em 21 de Maio de 2015.

BLUNDELL, Richard; BOND, Stephen. Initial conditions and moment restrictions in dynamic panel data models. Journal of Econometrics, v. 87, p. 115-143. 1998.

BÓGEA SOBRINHO, Leonel R.; SHENG, Hsia Hua; LORA, Mayra I. Country Factors and Dynamic Capital Structure in Latin American Firms. Revista Brasileira de Finanças, n. 2, v. 10, p. 267-284. 2012.

CORE, John.; HOLTHAUSEN, Robert.; LARCKER, David. Corporate governance, CEO compensation and firm performance. Journal of Financial Economics, v. 51, n- 3, p. 371-406, 1999.

CRONQVIST, Henrik.; MAKHIJA, Anil.; YONKER, Scott. Behavioral consistency in corporate finance: CEO personal and corporate leverage. Journal of Financial Economics, v.103, p. 20-40, 2012.

CORREA, Carlos.; BASSO, Leonardo; NAKAMURA, Wilson. A estrutura de capital das maiores empresas brasileiras: Análise empírica das teorias de pecking order e trade-off usando panel data. Revista de Administração Mackenzie, v.14, n. 4, pp.106-133, 2013.

CUSTÓDIO, Cláudia.; METZGER, Daniel. Financial expert CEOs: CEO’s work experience and firm's financial policies. Journal of Financial Economics, v.114, n. 1, p. 125-154, 2014.

DURAND, David. Cost of debt and equity funds for business: trends and problems of measurement. In: Conference on Research on Business Finance. New York: National Bureau of Economic Research, 1952.

FRANK, Murray Z.; GOYAL, Vidhan K. Corporate leverage: How much do managers really matter?. Working paper, 2007. Disponível em: <http://citeseerx.ist.psu.edu/viewdoc/download?doi=10.1.1.470.7472\&rep=rep1\&type=pdf>. Acesso em: 21 de Maio. 2015.

FRANK, Murray Z.; GOYAL, Vidhan K. Trade-off and Pecking order theories of debt. Handbook of Corporate Finance. 1. Ed. Amsterdam: Elsevier, pp.136-171, 2008. 
GRAHAM, John.; LEARY, Mark.; ROBERTS, Michael. A century of capital structure: The levering of corporate America. Working paper No. 19910, 2014. Disponível em: < http://www.nber.org/papers/w19910>. Acesso em: 21 de Maio. 2015.

HILARY, Gilles.; HUI, Kai. Does religion matter in corporate decision making in America?. Journal of Financial Economics, v. 93, n. 3, p. 455-473, 2008.

JENSEN, Michael.; MECKLING, William. Theory of the firm: managerial behavior, agency costs and ownership structure. Journal of Financial Economics, v. 3, n. 4, p. 305-360, 1976.

LEMMON, Michael.; ROBERTS, Michael.; ZENDER, Jaime. Back to the beginning: Persistence and the cross-section of corporate capital structure. The Journal of Finance, v. 63, n. 4, p. 1575-1608, 2008.

MACHADO, Márcio A. V.; MEDEIROS, Otávio R. de; EID JÚNIOR, W. Problemas na mensuração da estrutura de capital: evidências empíricas no Brasil. Brazilian Business Review, v. 7, n. 1, p. 24-47. 2010.

MALMENDIER, Ulrike.; TATE, Geoffrey. CEO overconfidence and corporate investment. The Journal of Finance, v. 60 , n. 6, 2006.

MISHRA, Dev. Dark side of CEO ability: CEO general managerial skills and cost of equity capital, Journal of Corporate Finance, v.29, pp.390-409, 2014.

MODIGLIANI, Franco.; MILLER, Merton. Corporate income taxes and the cost of capital: a correction. American Economic Review, v. 53, n. 3, p. 433-443, 1963.

MODIGLIANI, Franco.; MILLER, Merton. The cost of capital: Corporate finance, and the theory of finance. American Economic Review, v. 47, n. 3, p. 261-297, 1958.

NAKAMURA,W.; MARTIN, D.; FORTE, D.; CARVALHO,A.; FERREIRA, A.; CINTRA, A. Determinantes da estrutura de capital no mercado brasileiro: Análise de regressão com painel de dados no período 1999-2003. Revista de Contabilidade e Finanças da Universidade de São Paulo, n.44, p.72-85, 2007.

PAPADAKIS, Vassilis M.; BARWISE Patrick. How much do CEOs and Top Managers matter in strategic decision making?. British Journal of Management, v.13, n. 1, p.83-95, 2002.

PEROBELLI, Fernanda. FAMÁ, Rubens. Determinantes da estrutura de capital: aplicação a empresas de capital aberto brasileiras. Revista de Administração da Universidade de São Paulo, v. 37, n.3, p.33-46, 2002.

PETERAF, Margaret. The cornerstones of competitive advantage: A resource-based view. Strategic Management Journal, v. 14, n. 3, p. 179-191, 1993.

RAJAN, Raghuram G.; ZINGALES, Luigi. What Do We Know about Capital Structure? Some Evidence from International Data. The Journal of Finance, v. 50, n. 5, p. 1421-1460. 1995.

ROCHA, Flávio. Determinantes da estrutura de capital aberto e o nível de endividamento nas empresas de capital aberto: um estudo comparativo entre Argentina, Brasil e os Estados Unidos.2014. 283 f. Tese (Doutorado em Administração) - Centro de Pós-Graduação e Pesquisas em Administração da Universidade Federal de Minas Gerais. Belo Horizonte: UFMG, 2014.

ROTEMBERG, Julio.; SALONER, Garth. Visionaries, Managers, and Strategic Direction. The RAND Journal of Economics, v. 31, n. 4, p.693-716, 2000.

SERFLING, Matthew. CEO age and the riskiness of corporate policies. Journal of Corporate Finance, v. 25, n. 1, p. 251273, 2014.

TERRANCE, Jalbert.; RAMESH, Rao.; MERCEDES, Jalbert. Does school matter? An empirical analysis of CEO education, compensation and firm performance. International Business and Economics Research Journal, v. 1, n. 1, p. 83-98, 2002.

WERNERFELT, Birger. A resource-based view of the firm. Strategic Management Journal, V. 5, p. 171-180, 1984.

WELCH, Ivo. Common Problems in Capital Structure Research: The Financial-Debt-to-Asset Ratio, and Issuing Activity vs. Leverage Changes. NBR Working papers series. 2006. Disponível em: < http://papers.ssrn.com/sol3/papers.cfm?abstract_id=931675>. Acesso em: 25 de Fev. 2013.

WELCH, Ivo. Two Common Problems in Capital Structure Research: The Financial-Debt-to Asset Ratio and Issuing Activity versus Leverage Changes. International Review of Finance, v. 11, n. 1, p. 1-17. 2011.

WINDMEIJER, Frank. A finite sample correction for the variance of linear efficient two-step GMM estimators. Journal of Econometrics, n. 1, v. 126, p. 25-51. 2005.

YAM, Qin.; ZIMMERMAN, Monica.; JIANG, Crystal. An empirical study of the impact of CEO characteristics on the new firms time to IPO, Journal of Small Business Management, v. 49, n.1, pp.163-184, 2011.

YIM, Soojin. The acquisitiveness of youth: CEO age and acquisition behavior. Journal of Financial Economics, v. 108, p. 250-273, 2013. 